\title{
كلمهة العدد
}

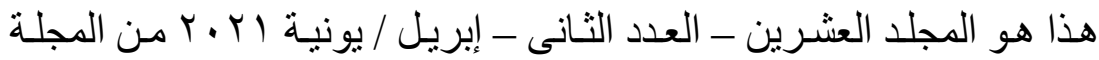

المصرية لبحوث الر أى العام ويحتوى على اثنا عشر بحثن.

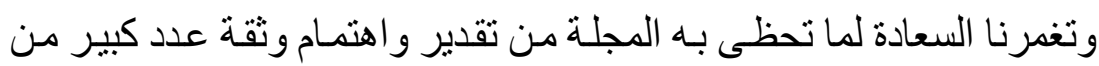

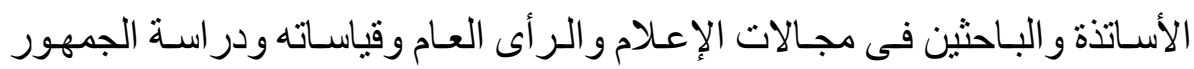

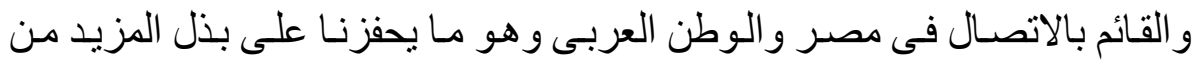

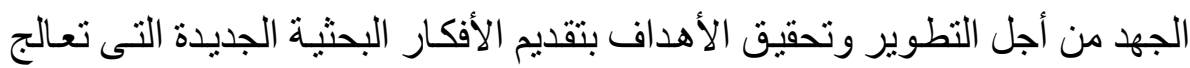

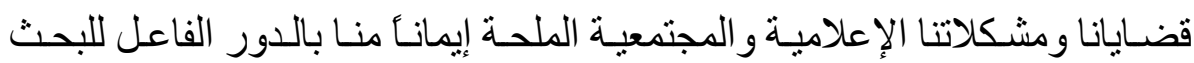
العلمى فى خدمة المجتمع .

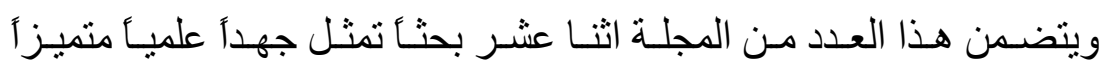
لمجموعة من الباحثين الذين ينتمون إلى مؤسسات أكاديمية مختلفة فى مجال الإعلام

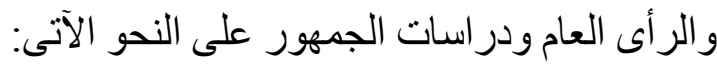

\section{أولاً: بحوث الصحافة وتأثير ها على الرأى العام:}

الاراسة الأولى بعنوان: "استراتيجيات خطاب صحافة التكنولوجيا العربية تجاه

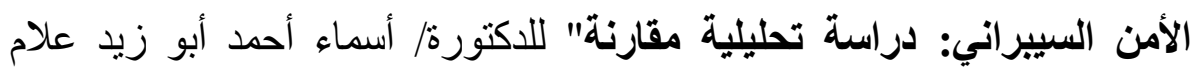

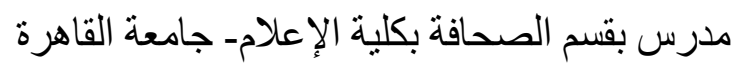
الاراسة الثانية بعنوان: "تمثيلات المرأة فى الصحافة الاقتصادية وعلاقتها بالواقع

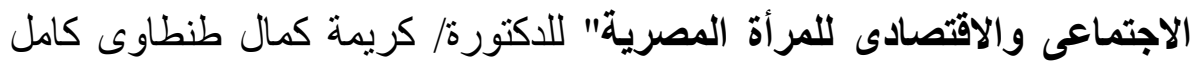

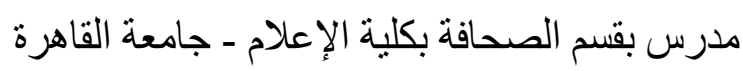
الاراسة الثالثة بعنوان: "توظيف تطبيقات الأكاء الاصطناعي لتحليل مشاعر

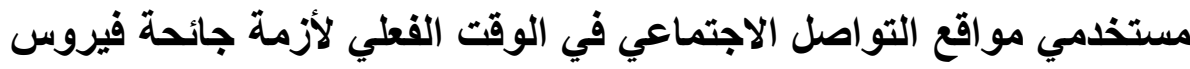

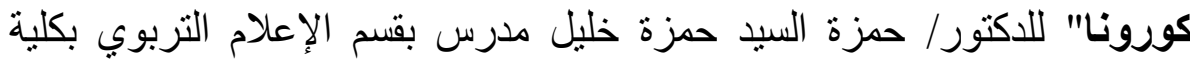
التربية النو عية - جامعة طنطا الاراسة الرابعة بعنوان: "التحديات التي تواجه التربية الإعلامية في مجال التعليم في ضوء التحول الرقمي" للاكتورة/ مروه محمد أحمد عوف مدرس بقسم الإعلام

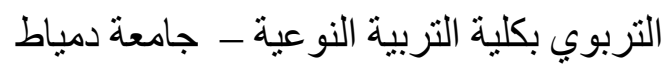


ثانياً: بحوث الإذاعة و التليفزيوذ والرأى العام:

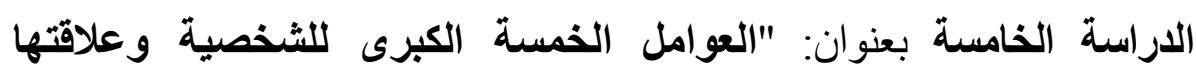

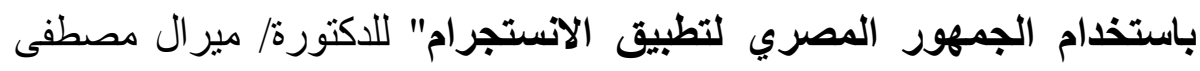

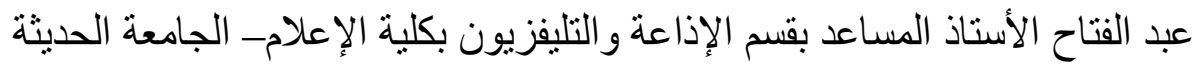
لالتكنولوجيا والمعلومات الاتل

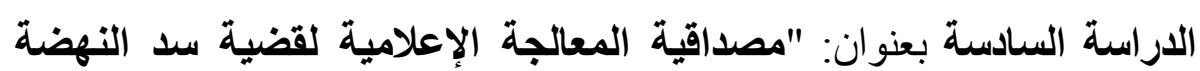

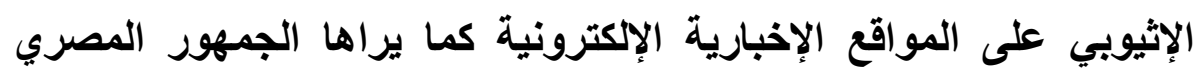

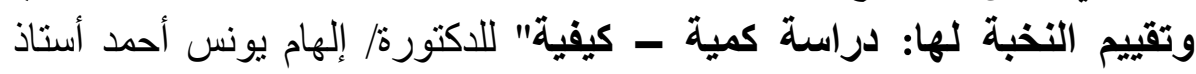

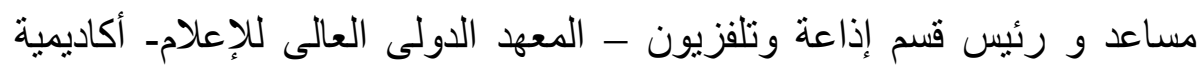
الثروق

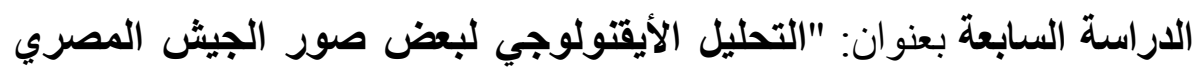

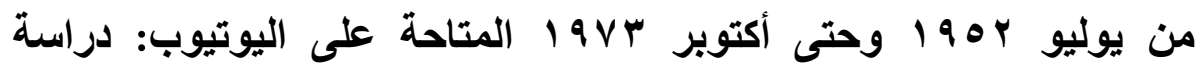

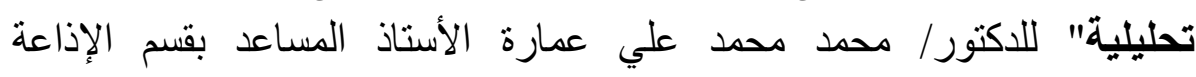

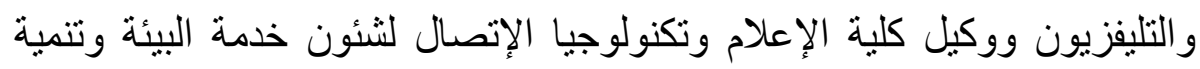
المجتمع جامعة جنوب الو ادي الئي الدراسة الثامنة بعنوان: "العلاقة بين متابعة الثباب لموقع الانستجرام وتنمية

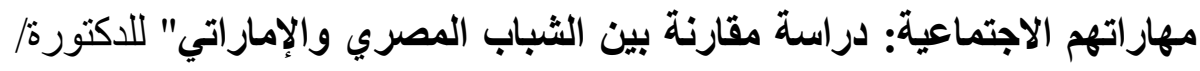

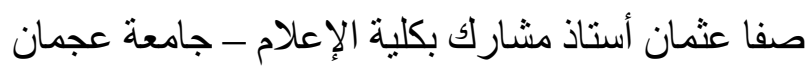

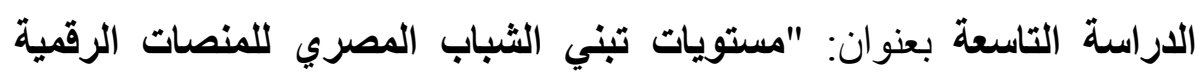

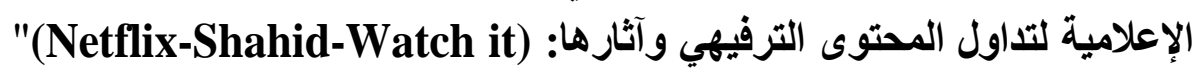

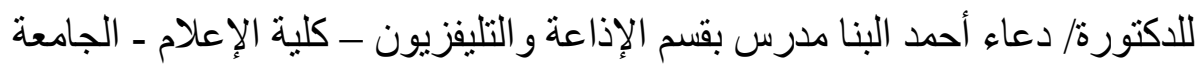
الحديثة للتكنولو جيا والمعلومات المبنات

الاراسة العاشرة بعنوان: "أثث القيادة التحويلية على تحسين الأداء الإعلامي

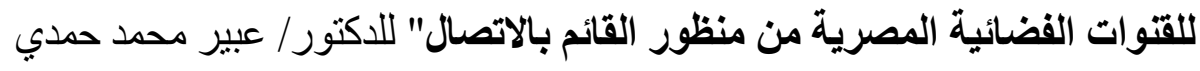

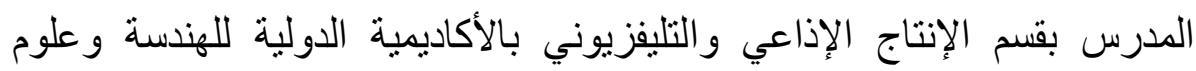

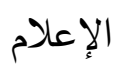


ثالثاً: بحوث الاتصالات التسويقية المتكاملة وبحوث الرأى العام:

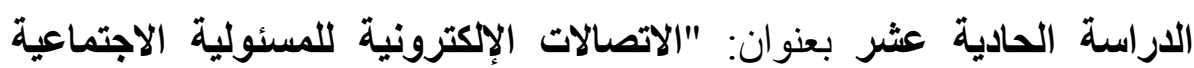

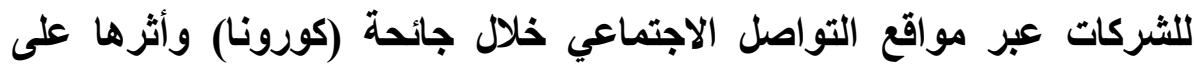

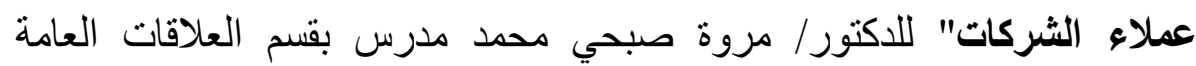

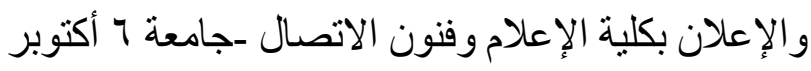

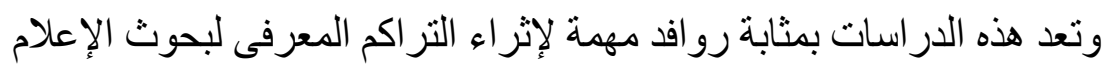

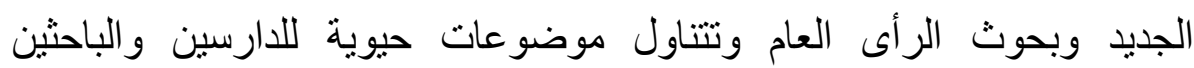

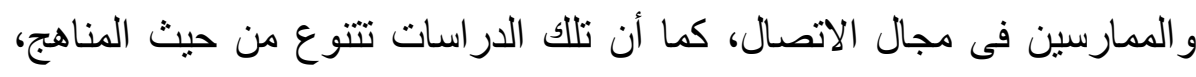

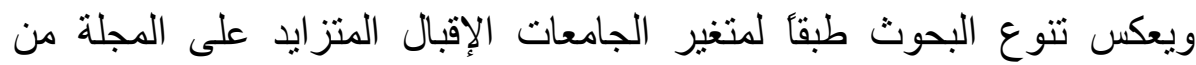

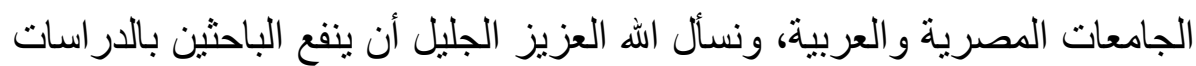

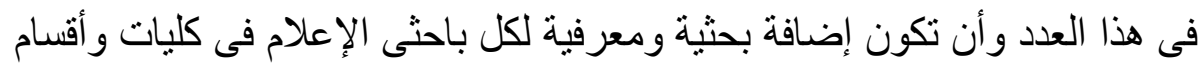
الإعلام المصرية والعربية.

$$
\text { والله ولى التوفيق }
$$

\section{أ. أ. حنان جنيد}

وكيل الكلية لثئون البيئة وتنمية المجتمع

ومدير تحريز المجلة 